\title{
CODIGO CIVIL DE 1852: LO NACIONAL Y LO IMPORTADO
}

\author{
César Luna Victoria León
}

\section{Introducción : precisión del tema}

Contra lo que sugiere el título, no se trata de investigar las "fuentes" del Código Civil de 1852 ni de determinar el origen de las diversas instituciones jurídicas que recogió. Algo de esto se desarrolla, pero no será lo más relevante.

La intención es otra. He querido ubicarme en el proceso de formación del Código para conocer con qué grado de eficacia el codificador logra incorporar o adaptar las ideas liberales prevalecientes en las tendencias codificadoras del siglo XIX (lo importado) para establecer normas que regulen situaciones nacionales (lo nacional).

Hay algunas ideas generalizadas que alientan este trabajo. El Código Civil de 1852 estuvo vigente 84 años (1852-1936), todo un record para la vigencia de los principales Códigos en el Perú. Mucho de eficaz debieron tener sus regulaciones para haber durado lo que duraron $i \ldots o$ es que los problemas no resueltos por el Código o los conflictos que éste creó se resolvieron al margen del Código o, inclusive, de la legalidad?

El proceso de formación del zúdigo también resulta atractivo. Si bien es cierto que el Código se promulga después de 30 años de fundada la República (1821-1852), no es menos cierto que en ese período se desarrollaron tendencias internas y externas que modificaban la legislación civil. A nivel interno debe destacarse que en ese período se dictaron 2 Estatutos Provisorios, 6 Constituciones, se aplicó el Código Civil Boliviano (durante la etapa de la Confederación Perú-Boliviana) y se dictaron diversos decretos especiales. A nivel externo, la fundación de la República coincide con el desarrollo y expansión de las ideas liberales occidentales recogi- 
das en las Constituciones, y las tendencias codificadoras inspiradas en el Código Francés de 1802.

Estas tendencias generaron una dialéctica con el Derecho de la Colonia, formalmente vigente en los primeros años de la República, superponiendo normas a ideas, a figuras jurídicas, a tradiciones y a costumbres. Probablemente nunca antes ni nunca más el Poder Judicial ha tenido ni tendrá tal capacidad discrecional para administrar justicia: el juzgador realmente dictaba derecho en sus resoluciones judiciales, porque no tenía un cuerpo normativo codificado para aplicarlo mecánicamente.

Los intereses en conflicto potenciados con la fundación de la República, por último, debieron estar muy atentos a la forma cómo se iba perfilando el Derecho Republicano. Todo esto debe resultar lo suficientemente atractivo para precisar de qué manera el Código Civil logra resolver las tendencias y también de qué manera las replantea $i . .$. o el codificador recreó un espacio de discusión a nivel sólo de la dogmática jurídica y se automarginó del conflicto de intereses?

En otras palabras: ¿El Perú tuvo finalmente un Código Civil porque lo necesitaba para regular situaciones no definidas o, sin resolverlo, lo promulgó como una necesidad formal de unificar normas dispersas? El planteamiento es esencial: o el Código Civil fue concebido por los codificadores como un instrumento de formación de la nacionalidad (como había sido concebido por los Estados Europeos, muy especialmente Francia) o el Código fue reducido a un símbolo del nuevo Estado (como la bandera, el escudo y el himno).

Para abordar el tema, primero realizo una referencia al contexto histórico y desarrollo el proceso de formación del Código. Los problemas elegidos para confrontar "lo nacional con lo importado" son tres: el problema del indio y la tierra (propiedad inmobiliaria), el matrimonio (concebible como sacramento o como contrato) $\mathrm{y}$, por último, el problema de los esclavos. La evaluación de la eficacia en la importación de ideas liberales para regular situaciones nacionales se comenta al final del trabajo, a modo de reflexión final. 


\section{El con tex to histórico}

El período comprendido entre el inicio de la República (18211824 ) hasta mediados del siglo XIX (1850 es el inicio de la explotación eficiente del guano) es un oscuro período de caos. Sin orden, sin administración, sin instituciones republicanas. El poder fue asumido por "caudillos militares".

La inercia del caos que sobrevino con la Independencia puede ser explicada por la falencia del aparato productivo. ". . . La Independencia fue, de inmediato en el Perú, un desastre para la economía nacional, más que para la de otros países. La guerra arruinó las explotaciones mineras y la infraestructura de las comunicaciones y agregó el bandolerismo y el caos; la desaparición de la burocracia colonial favoreció durante largo tiempo el desorden en el sistema administrativo y fiscal; y el triunfo de los criollos vino a redundar de inmediato en provecho de la anarquía y del latifundio ..." (Basadre 1939: Tomo I Págs. 269-270).

A la depresión de la actividad minera (iniciada en tiempos de la Colonia) se agregó la crisis de la agricultura (latifundio improductivo en la sierra, confiscaciones de propiedades rurales de los españoles en la costa y las limitaciones a la esclavitud que constituían la mano de obra de las haciendas más dinámicas). Si bien el guano aparece como producto explotable en 1840, el inicial sistema de consignatarios no resulta económicamente rentable sino diez años después. Hasta esa fecha, poco se nota la presencia de un espíritu inherente al desarrollo de un capitalismo nacional. $\mathrm{Ni}$ grandes propietarios de negocios en progreso ni patrones de empresas había en número suficiente. No funcionaban bancos ni en provincias ni en Lima. Sólo se habían presentado proyectos para establecerlos (véase Basadre 1939: Tomo II, Pág. 309).

En ese contexto, se explica fácilmente cómo las guerras de Independencia fuesen solventadas por empréstitos (rentistamente cobrados después en la época del guano) y que los únicos ingresos fiscales relevantes fuesen los ingresos por comercio exterior (aduanas) y el tributo a los indígenas, para cuya recaudación se aprovecharon las estructuras de poder provincial de la Colonia que sobrevivieron en los primeros años de la República. 
Desde el inicio de la República había déficit en la balanza comercial. Por lo general, las exportaciones sólo representaban el 75\% de las importaciones y las normas estrictas de control de comercio exterior sólo favorecieron el contrabando y, por consiguiente, la disminución de los ingresos fiscales por aduanas. Para completar el caos económico, la naciente República no funcionó con Presupuesto hasta el primer gobierno de Castilla (1845), a pesar que todas las Constituciones $(1823,1826,1828,1834$ y 1839) establecían tal obligación. (Véase Basadre 1939: Tomo III, Pág. 165, y Tomo I, Págs. 217-218).

Las diversas y sucesivas Constituciones no hacen sino reflejar la falta de continuidad de las formas republicanas, los diversos ensayos que se hicieron a nivel político y la inestabilidad que la velocidad de tales cambios inspiraba. " . . el 12 de noviembre de 1823 se promulga la primera Constitución propiamente peruana, idealista, liberal. ....El país diseñado por tal instrumento no tiene tiempo de cuajarse pues el 30 de noviembre de 1826 se promulga una constitución, de carácter autoritario que establece la presidencia vitalicia de Bolivar. El 18 de marzo de 1828 se promulga otra nueva Constitución, que retoma la posición liberal. Pero esta tenía carácter experimental y debía durar solamente cinco años. Es así como el 10 de junio de 1834 se promulga una cuarta constitución en la que se realizan pocos cambios con relación a la anterior. Con motivo del establecimiento de la Confederación Perú-Boliviana se promulgan dos constituciones más en muy breve plazo: el 17 de marzo de 1836 se da en Sicuani la Constitución del Estado SudPeruano y el 3 de agosto del mismo año se da en Huaura la del Estado Nor-Peruano. Además, el $1^{\circ}$ de mayo de 1837 , reunidos en Tacna los representantes de los tres países confederados, proclaman la constitución de la Confederación. Sin embargo, ésta no llegó a tener vigencia. El 10 de noviembre de 1839 se promulga la denominada "Constitución de Huancayo". . . A la muerte del presidente Gamarra, dicha Constitución fue dejada en suspenso entre 1842 y 1845 ; pero su autoridad fue restablecida por don Ramón

Castilla hasta el 22 de octubre de 1855 en que fue declarada derogada por la voluntad popular de la Nación. El 26 de julio de 1855 se adoptó un Estatuto Provisorio y el 19 de octubre de 1856 se promulgó una nueva constitución de carácter marcadamente liberal. La incomodidad de Castilla ante la falta de compromiso de es- 
ta última constitución entre el espíritu liberal y la necesidad de un gobierno más enérgico llevó a la Constitución "moderada" del 13 de noviembre de 1860 , cuya vigencia ha sido la más larga en la historia del Perú. En efecto, salvo breves interrupciones (1867-1868 y 1879-1885), la constitución de 1860 estuvo vigente hasta 1920 ... (Trazegnies 1980, Págs. 151-153).

Crisis económica, desorden administrativo y caos político no son sino manifestaciones de la ausencia de una burguesía peruana a tono con el Estado liberal que formalmente se estaba declarando. La reinterpretación de la historia de la emancipación realizada por Bonilla es explicativa de esta ausencia de clase hegemónica en el Perú y la necesidad que tuvieron de concurrir los grupos argentinos y chilenos primero (1821 con San Martín) y colombiano-venezo. lanos después (1824 con Bolívar) para consumar una Independencia cuya gestación sólo había involucrado antes movimientos regionales andinos (rebeliones de Túpac Amaru II y Pumacahua en el sur, principalmente) (Véase Bonilla 1972 y 1974).

La falta de hegemonía de una clase burguesa liberal permitió la sobrevivencia de una aristocracia colonial y el fortalecimiento de una oligarquía terrateniente de nivel regional cuyo poder se incrementará con la expansión del latifundio y el dinamismo de la agricultura para la exportación a mediados del siglo XIX y, más precisamente, luego de la guerra con Chile (1879-1884). Pero en los primeros años de la República (que es lo que interesa), el conflicto de clases y grupos no tuvo escenario. El vacío de poder fue llenado, a nivel político, por los "caudillos militares" que usufructuaban el prestigio ganado en la guerra de la Independencia y, posteriormente, en las luchas civiles auspiciadas por ellos mismos.

En este contexto, la identidad nacional se define por oposición. La patria no será el Perú sino todo aquello que no es España. Las ideas iniciales sobre una gran patria subregional (el sueño de Bolívar primero y la Confederación Perú-Boliviana de Santa Cruz después) confunden aún más. En rigor, en el contexto histórico, la formación del Perú como Estado se define luego que se definen sus fronteras norte (la Gran Colombia) y sur (Bolivia). Inicialmente, nada de extraño tenía que los Presidente del Perú fuesen naturales de otros territorios (caso del boliviano Santa Cruz o del gran 
colombiano La Mar) y no por ello dejaban de ser llamados peruanos. (Basadre 1939: Tomo I, Págs. 269-270).

\section{El proceso de formación del Código}

La existencia de Códigos en el sentido moderno no se llega a concebir sino a fines del siglo XVIII, pero se divulgan a principio del siglo XIX. La tendencia coincide con el ocaso del Estado Absolutista en Europa, donde existian un conjunto de dificultades de orden jurídico en relación con la existencia de derechos regionales, señoriales o aristocráticos, territoriales y municipales que se superponían y generaban contradicciones. La necesidad de unificar estas regulaciones y de imponerlas sobre un territorio es una necesidad del Estado Moderno y un instrumento que se utilizó para consolidar la hegemonía de grupos burgueses y culminar el proceso de formación de las nacionalidades modernas. Al desarrollo de la necesidad de unificación contribuyó la aparición de la teoría del jus naturalismo consagrando que el fundamento del derecho es la razón y que, por consiguiente, el derecho puede enunciarse en forma escrita y coordinada.

El proceso de codificación del siglo XIX fue producto de diversas tendencias. Los gobernantes tenían interés en que se hiciera la codificación para de ese modo disminuir los fueros o derechos especiales; los filósofos para darle al derecho un sentido de órdenes con caracteres abstractos y los juristas por razones técnicas; pero al mismo tiempo, todas estas razones coincidían con la moda del derecho natural como fuente del derecho privado.

Al mismo tiempo, la búsqueda de unos textos legales simples y accesibles correspondió al espíritu individualista de la época. Cada cual, podía calcular de antemano lo que le era dable esperar de la norma jurídica, sus relaciones jurídicas debían ser reguladas entonces por normas breves, precisas y claras.

La fundación de los Estados Hispanoamericanos, entre ellos la República Peruana, coincide con el comienzo de la expansión mundial de esta tendencia codificadora en el derecho occidental. La necesidad de los Códigos, en general, y del Código Civil en particular fue comprendida por los gobernantes peruanos desde muy 
temprano. El 31 de diciembre de 1825 Bolívar nombró una comisión de 12 personas destinadas a prepararlos, pero esta comisión sólo llegó a reunirse una sola vez. En 1832 el gobierno nombra otra comisión, pero el único trabajo realizado en el seno de ésta fue un discurso de Vidaurre sobre recusaciones. La Constitución de 1834 incluyó un artículo que facultaba a la Corte Suprema para que presentase en cada legislatura anual el proyecto de uno de los códigos, empezando por el civil. Bajo la presidencia de Vidaurre se elabora el proyecto de Código Civil conocido como el proyecto de Vidaurre. El proyecto de Vidaurre no prosperó por su marcado anticlericalismo (tratado más extensamente en el rubro 5 sobre el matrimonio) y por su deficiente técnica jurídica. En rigor, el proyecto de Vidaurre era más un texto de dogmática jurídica, aunque no coherente. La soberbia de Vidaurre le impidió tomar como base algún Código preexistente. Santa Cruz prefirió adoptar los códigos bolivianos en 1836 .

El Código Civil boliviano fue en su mayor parte resultado de un proceso de recepción mecánica del Código Francés. El Código fracasó fundamentalmente porque se puso en vigencia en el Perú como una concesión al Estado Boliviano propulsor de la Confederación $y$, consecuentemente, fue dejado de lado una vez caída la Confederación. En cuanto al Código mismo, suscitó reticencias porque fue promulgado simultáneamente con el Código Penal y el de Procedimientos Judiciales, toda una revolución en el mundo de la magistratura y el foro. El Estado Nor-Peruano derogó los Códigos el 31 de julio de 1838 (duraron sólo año y medio). En el sur duraron seis meses más, hasta la caída de la Confederación en enero de 1839.

En 1845 el gobierno de Castilla nombra una nueva Comisión. El proyecto fue sometido al Parlamento que, entre 1847 y 1849 , tachó o modificó varios artículos. La Ley del 21 de diciembre de 1849 crea una última Comisión encargada de revisar el proyecto de la Comisión de 1847. La Comisión Revisora, extralimitándose en sus atribuciones, introdujo enmiendas sustanciales sin llegar a culminar un nuevo proyecto. A pesar de las observaciones del Consejo de Estado sobre lo incompleto del proyecto, Castilla promulga el Código el 22 de noviembre de 1850, casi en vísperas de concluir su período presidencial. Su sucesor, José Rufino Echeni- 
que suspendió los efectos del decreto de Castilla (cuya versión del Código no llegó a estar vigente) y por ley del 7 de junio de 1851 se nombró una comisión de las dos cámaras legislativas para que procediesen a la revisión final del Código. El Código fue finalmente promulgado por el mismo Echenique el 28 de julio de 1852.

Es pues hacia 1840, caída ya la Confederación y aparecido el guano como recurso de exportación, que se recupera cierta tranquilidad y estabilidad política que permite la labor Codificadora. Al margen de los antecedentes del Proyecto de Vidaurre y del Código Civil de la Confederación Perú-Boliviana, la labor Codificadora duró entre 1845 (la primera comisión de Castilla) y 1852 (fecha de promulgación del Código).

Sin embargo, como es evidente, el derecho civil republicano no empieza con el Código. La transformación del derecho privado se inicia a través de artículos constitucionales, leyes o decretos. Así, cuando por decreto de San Martín del 12 de agosto de 1821 se declara que todos los hijos de esclavos que hubieran nacido o nacieran en el territorio del Perú desde el 28 de julio de 1821 son libres, queda modificado el régimen de las personas naturales. El de las personas por su estado civil se altera con los decretos del 4 de octubre de 1821 sobre naturaleza y ciudadania y el 17 de octubre de ese año sobre extranjeros. El Congreso de 1822 suprime los títulos de nobleza en el Perú con el fin de dar golpe a la ilusión monárquica de San Martín y esta disposición repercute también en el derecho privado en el sentido de que no se podía hacer la división de las personas en nobles y plebeyos. En diversos artículos constitucionales se reconoce la igualdad ante la ley, la supresión de los empleos y privilegios hereditarios, la supresión de las vinculaciones laicales. Similar espíritu tienen los reiterados decretos que colocan al indio en idéntica condición a los demás peruanos, derogando tácitamente la legislación que los protegía.

Pero toda esta innovación en el derecho privado se debe precisamente a la vigencia del derecho colonial. Esta es una de las características en la formación del derecho peruano. Así como en la Colonia sobrevivieron de algún modo regulaciones de la época incaica, así en el período inicial de la República sobrevivió el derecho de la Colonia. En términos generales, la Independencia fue po- 
lítica, se derriba al gobierno español, pero no insurge contra lo hispánico ni contra lo occidental. No hay pues vacío jurídico al producirse la transición de una época a otra; por el contrario habrá continuidad. Cierto es que el derecho de un lado se nacionaliza al concretarse a lo peruano, pero de otro lado también se extranjeriza mediante un proceso gradual de recepciones que lo convierte en un mosaico de importaciones.

En este periodo de formación del Código, el derecho privado incorpora diversos elementos, provenientes de diversas fuentes. Basadre clasifica estos elementos en:

1. La Declaración de la Independencia Nacional, con sus repercusiones sobre las personas desde el punto de vista de su división entre peruanos y extranjeros.

2. El concepto de la igualdad entre los peruanos ante la ley y con ello la abolición de los títulos de nobleza.

3. La acentuación de un régimen resueltamente individualista en la propiedad inmueble, con las leyes de abolición de las vinculaciones laicales en general y de los mayorazgos en especial, así como con las leyes y decretos sobre la reducción del canon o renta de los censos.

4. La supervigilancia sobre el clero regular a través de los decretos sobre el número y las obligaciones de los religiosos.

5. La reglamentación de la esclavitud, dejando libres a determinados esclavos primero y entregando luego a los hijos de estos bajo patronazgo de sus amos hasta los 50 años.

6. La reglamentación de la propiedad intelectual.

7. La victoria de la teoría de la codificación del derecho.

Estas diversas fuentes que influyeron en los codificadores pueden ser igualmente agrupadas, a tenor de Basadre, en las siguientes:

1. El antiguo derecho romano, de donde provienen las definiciones y distinciones jurídicas en general, el cuadro de los derechos reales, las modificaciones de la propiedad, la doctrina de la accesión, de la servidumbre, sólo por citar algunos. También son romanizados los artículos sobre las obligaciones y contratación, con determinadas concesiones a la realidad del sistema 
económico y especial proveniente del coloniaje.

2. El Derecho castellano influyó también en su doble vertiente de derecho civil peninsular (elaborado para España) y como derecho especial para América (derecho indiano). El derecho indiano sobrevivió a la fundación de la República e inclusive al propio Código Civil. No obstante, fue propósito declarado de legisladores primero y codificadores después, el derogarlo, dejando sin efecto las medidas tutelares para los indígenas. La derogación formal del derecho indiano era congruente con los postulados de la filosofía liberal (teórica y racionalista) que no podía comprender sino al individuo en abstracto. Equiparando al indio con ese individuo abstracto, los codificadores creyeron hacerle un servicio, porque no quedaba formalmente en condición más baja que la del resto de los peruanos; sin visualizar que esta supuesta igualdad jurídica permitiría ahondar las diferencias reales.

3. El derecho español perviviô. Algunos ejemplos darán muestra de ello. La institución de la esclavitud tiene origen colonial y, consecuentemente, las disposiciones del código sobre manumisión, ingenuos, siervos y libertos provienen de este derecho. La posició: :inal del matrimonio como sacramento, la actitud antidivorciita y la sujeción al Concilio de Trento también provienen del derecho colonial, aunque la influencia mas directa corresponda al derecho canónico. Las vinculaciones a la propiedad inmueble también sobrevivieron a la fundación de la República. La legislación previa y el mismo Código pretendieron dinamizar el libre comercio inmobiliario aboliendo las vinculaciones laicales, pero sobrevivieron las eclesiásticas.

4. El derecho canónico, además de su sobrepresencia en el tema del matrimonio, tuvo influencia indudable en las regulaciones sobre los clérigos, la desigualdad de los hijos, las capellanias y las vinculaciones eclesiásticas.

5. Pero, por sobre todas las fuentes, el Código de 1852 se gestó bajo la fascinación de la revolución francesa. Toda la adecuación de la vida jurídica giró en torno al principio de la igualdad. La influencia francesa opera directamente a través del Código napoleónico $\mathrm{e}$, indirectamente, a través del Código de Santa Cruz.

La diversidad de fuentes y la ausencia de un grupo hegemóni- 
co que impusiera coherentemente sus ideas en función de su propio proyecto nacional y la incipiente formación no sólo de las ideas sino de la nueva vida republicana que no perfilaba aún grupos e intereses, determinó un Código contradictorio en sus aspectos principales. Es cierto que a nivel de diversas figuras e instituciones jurídicas (contratos y propiedad inmobilaria) se limitó a organizar y retocar las normas ya expresadas en las tendencias codificadoras liberales, lo que le permitió presentarse para muchos comentaristas como un Código sobrio y a veces elegante con la forma. Pero a este nivel poco importante aportó a la cultura jurídica universal. En la mayoría de las instituciones sus reglas fueron estereotipadas y reprodujeron lo ya establecido en otras legislaciones, principalmente la francesa.

Pero el Código no fue una importación mecánica del Código francés. Fue liberal al excluir en su tratamiento al indio y a la comunidad indígena (ahora comunidad campesina). Ningún artículo mencionó al indio y pretendió abolir la comunidad. Pero fue conservador al regular la esclavitud y someter la regulación del matrimonio a las disposiciones canónicas. Esta contradicción para resolver problemas y situaciones nacionales en un caso de modo liberal y en otro de modo conservador es la que pretende ser analizada en los rubros precedentes y, en su caso, evaluar la eficacia de la "importación" de normas.

Por último, desde el punto de vista económico, el Código $\mathrm{Ci}$ vil como a su turno el Código de Comercio carecieron de importancia. Los Códigos fueron elaborados y promulgados antes de que el Perú sintiera los efectos de la acumulación de los excedentes de la explotación del guano y casi sin prever que tal acumulación pudiera darse. Los codificadores se preocuparon más por la propiedad inmueble. No existía hacia 1851 Bancos de emisión ni descuentos, bancos hipotecarios, sociedades de seguros, ni empresas industriales o financieras. Cuando aparecieron, su vida económica y jurídica se realizó al margen de los Códigos, pues estos fueron superados por la propia dinámica económica.

(Para todo el rubro, véase Basadre 1937 Tomo III Págs. 180 a 193, 218, 307, 316 y 317; Basadre 1937 Págs. 324 a 375; y Basadre 1954,365 a 391 ). 


\section{El problema del indio y la tierra (propiedad inmobiliaria)}

El Código Civil no reguló la situación del indio de modo directo. Pero si reguló la propiedad inmobiliaria y, junto con la legislación precedente, estableció mecanismos para su libre comercio. Conforme al pensamiento liberal, la igualdad jurídica entre los hombres era entendida también como la libertad para comprar y vender. En este contexto, la comunidad indigena no llegó a ser comprendida como una realidad económica y jurídica, sino como una forma colectiva de propiedad, que era necesario abolir junto con las demás vinculaciones precisamente para promover la adjudicación y disposición individual de las parcelas.

El indio, en el periodo de formación del Código dejó de ser considerado como tal sólo desde un aspecto parcial del derecho. Para comprender el rol ideológico que desempeñó el Código Civil se debe comprender también la consideración del indio como ciudadano (para el derecho constitucional) y como contribuyente (para efectos fiscales). Del tratarniento global que el derecho republicano del siglo XIX da al indio, podremos extraer mejores elementos de comprensión sobre la omisión del tema del indio en el Código Civil.

\subsection{El programa liberal sobre la tierra}

El tema del indio no puede ser entendido sin comprender también el rol de la tierra. La vinculación del indio con la tierra, desde la organización del imperio incaico, fue política antes que jurídica. El Estado Inca como después la metrópoli española se reservaron la propiedad sobre la tierra como un legítimo derecho derivado de la Conquista. Establecida la dominación política, la tierra era adjudicada por el Estado a los "comunes" para su explotación. Este origen de la posesión justificaba la extracción de excedentes sea como una colaboración comunitaria en el Estado Inca o, más refinada, bajo forma de tributo en la Colonia.

Durante la Colonia, las Leyes de Indias persiguieron proteger las tierras poseidas por los indios para satisfacer las propias necesidades de subsistencia del sistema económico: producción agraria para los centros mineros y urbanos y concentración de mano de 
obra para las minas. El desarrollo del latifundio como despojo de tierras no ocurre inicialmente sobre las tierras adjudicadas a las comunidades sino sobre las tierras excedentes que el Estado Inca asignaba a la nobleza y al culto religioso. Sólo en el siglo XVIII con el desarrollo de la "encomienda" el latifundio crecerá sobre el despojo de tierras comunales, cuyo proceso durará hasta el siglo XX. Conforme al concepto legal de la institución, el "encomendero" era un encargado del cobro de los tributos y de la organización y cristianización de los tributarios (los indígenas). Sin embargo, en la realidad de las cosas, era un señor con poder sobre el territorio y las personas encomendadas. Estos grandes feudos, lejos de dividirse en el transcurso del tiempo, se concentraron y consolidaron en pocas manos a causa de las vinculaciones (gravámenes perpetuos) que inmovilizaron el tráfico de la propiedad inmobiliaria (mayorazgos, capellanías, fundaciones, patronazgos). (véase Mariátegui 1928 pág. 74 y Costa 1981 págs. 15 y 19).

El legislador en el inicio de la República implementó el programa liberal, no sólo por razones ideológicas. Era consciente también de la necesidad de dinamizar la actividad agraria destruida por la Guerra de Independencia. Así, el Decreto Supremo de 1824 estatuyó la libertad absoluta de enajenación; el Decreto Supremo de 1825 señaló que ésta sólo podría aplicarse a partir de 1850 y la Ley de 1828 que sólo podrían enajenar sus propiedades quienes supieran leer y escribir. Curioso retroceso en el pensamiento liberal de la libre enajenación de tierras, pero esta suerte de relativo proteccionismo al indígena no se aplicó en la realidad. En todo caso, dispositivos constitucionales posteriores consagraron que "... todas las propiedades son enajenables" (Art. 160 de la Constitución de 1828, repetida por la Constitución de 1839).

Este proceso de liberación de la propiedad agraria no sólo debía afectar a la comunidad indígena. Estaba también diseñada para afectar las "vinculaciones" sobre las que se asentaba el poder de la aristocracia. Las mismas Constituciones de 1828 y 1839 citadas expresaron que no se reconocian ". . . empleos ni privilegios hereditarios ni vinculaciones laicales ...". En consecuencia, a nivel legal, el periodo de formación del Código Civil coincidió con la abolición formal de la propiedad comunal y la propiedad aristocrática. 
Sin embargo, la abolición no fue del todo efectiva. Precisamente por el espíritu liberal, la labor del legislador civil se restringió a eliminar las trabas conservadoras que impedían el libre comercio. Dejó intactas otras estructuras. El Estado liberal del "dejar hacer, dejar pasar" no estaba dispuesto ni tampoco concibió mecanismos de protección ni de promoción agrarias. Esta opción (u omisión) resultó finalmente decisiva para el fracaso del programa liberal. En lo que se refiere al indio, resultaron poco eficaces las normas que abolieron los trabajos gratuitos y el reparto de tierras, en cambio sí fue eficaz la posibilidad de enajenación de sus tierras. Contrariamente, la aristocracia latifundista, aún en el poder al inicio de la República, conservó intactos sus derechos sobre la tierra, pese a la abolición de las vinculaciones laicales, reteniendo el poder sobre la tierra también retuvo el poder sobre el trabajo servil de los indios (véase Mariátegui 1928 pág. 46).

Por último, se debe destacar que el codificador no fue congruente con su planteamiento en materia de propiedad. Al omitir todo tratamiento sobre el indio no hacía sino continuar el pensamiento liberal de la legislación civil precedente. Pero esta opción liberal no se aplicó plenamente a las demás "vinculaciones inmobiliarias". Subsistieron y fueron reguladas por el Código las capellanías (vinculaciones eclesiásticas) y el patronazgo.

\subsection{La contribución de indigenas}

El tributo fue establecido por el régimen colonial, como un reconocimiento que los indígenas debían a la soberanía de la Metrópoli. En la última forma que alcanzó la encomienda, a través de su versión histórica, no fue sino la subrogación en el cobro del tributo, hecha con consentimiento de la Metrópoli en beneficio de algunos particulares. Con la fundación de la República, los indios al ser igualados en todos sus derechos a los demás peruanos, se vieron beneficiados con la abolición de diversas formas serviles, entre ellas el tributo. No obstante, se restableció por decreto del 11 de agosto de 1826 , con las mismas características que tuvo durante la Colonia. Para cobrarla se aplicó la instrucción del $1^{\circ}$ de junio de 1784 , con ligeras alteraciones.

Para el Fisco Nacional, la contribución de indígenas no era 
poca. Por lo general representaba más del $80 \%$ del total de ingresos fiscales por impuestos directos (ver Cuadro 2) y estos impuestos directos representaban alrededor de la mitad del total de ingresos corrientes, hasta la percepción de ingresos derivados de la explotación del guano (ver Cuadro 1).

\section{CUADRO 1}

\section{COMPOSICION INGRESOS CORRIENTES DEL GOBIERNO PERUANO}

$\begin{array}{lcccc}\text { Año } & \text { Total } & \text { Guano } & \begin{array}{c}\text { Participación Porcentual } \\ \text { Aduanas }\end{array} & \text { Imp. Directos } \\ & \text { (Pesos) } & & & \\ 1846 & 4 ' 191,000 & 0.6 & 55.3 & 44.0 \\ 1847 & 4 ' 191,000 & - & 56.9 & 43.0 \\ 1848 & 5 ' 322,423 & - & 43.9 & 56.0 \\ 1849 & 5 ' 322,423 & - & 46.5 & 53.5 \\ 1850 & 5 ' 450,976 & 5.5 & 31.9 & 62.5 \\ 1851 & 5 ' 450,976 & 5.5 & 40.8 & 53.7 \\ 1852 & 7 ' 113,500 & 26.7 & 43.7 & 29.5 \\ 1853 & 7 ' 113,500 & 26.7 & 42.1 & 31.1 \\ & & & & \\ \text { (Bonilla 1970, citado por Remy } & \text { 1986 Cuadro 1) }\end{array}$

Llama poderosamente la atención cómo el mensaje liberal de la legislación civil no tuvo correspondencia con la realidad fiscal concreta. Debe tenerse presente que las contribuciones directas, durante el periodo de formación del Código Civil, estuvieron integradas por la contribución de indígenas, la contribución de castas (aplicable a todos los no indígenas, esto es, a todos los demás peruanos) y patentes y tributos menores a la actividad industrial y a la propiedad inmobiliaria. Del Cuadro No. 1 se desprende con claridad que la presión tributaria directa sobre el resto de los peruanos no era mayor al $20 \%$, todo el peso recaía sobre los indígenas. 


\section{CUADRO 2}

\section{COMPOSICION INGRESOS FISCALES POR IMPUESTOS DIRECTOS}

$\begin{array}{cccr}\text { Año } & \begin{array}{c}\text { Total } \\ \text { (Pesos) }\end{array} & \text { Participación Porcentual } \\ & & & \\ & & & \\ 1826 & 1^{\prime} 471,190 & 70.65 & 29.35 \\ 1838 & 1^{\prime} 811,288 & 97.01 & 2.99 \\ 1847 & 1^{\prime} 569,084 & 84.56 & 15.44 \\ 1849 & \text { 1'542,537 } & 81.96 & 18.04 \\ 1953 & 1,667,060 & 83.98 & 16.02\end{array}$

(Dancourt 1902, citado por Remy 1986 Cuadro 1-B)

Para tener una idea de la magnitud de la presión tributaria, hay que considerar que el total de ingresos fiscales por impuestos directos nunca sobrepasó en el período más de dos millones de pesos anuales. Según Basadre este valor anual era similar al total de las propiedades rústicas y urbanas de los españoles que fueron secuestradas por la República a raíz de la guerra de independencia, según la memoria del Ministro de Hacienda José Larrea y Loredo expuesta en 1826 (Basadre 1939 Tomo I Pág. 229).

La poca importancia de la contribución de castas determinó que fuera abolida por la ley del 25 de setiembre de 1840 . Por decreto del 26 de setiembre de ese año, no obstante, en lugar de abolir la contribución de indígenas, se dieron reglas y preceptos para evitar corruptelas y abusos, con el ánimo de hacer más eficiente la acotación y recaudación del tributo, estableciéndose además la reestructuración de las matrículas de indígenas (relación de tributarios). La contribución de indígenas sólo desaparecería cuando los ingresos fiscales se incrementaron por la explotación del guano.

En consecuencia, mientras para la legislación civil el indio ya no era más un indio y se le igualaba en todos sus derechos a los demás peruanos, permitiendo la libre enajenación de las tierras y la 
abolición de sus comunidades; en cambio para la realidad fiscal, el indio debería seguir subsistiendo en las mismas condiciones tributarias a las que había sido sometido a raíz de la conquista. Inclusive, para el analista de los ingresos fiscales, no se comprendía cómo el legislador civil pretendía abolir la condición del indígena sin prever sustitutoriamente otros ingresos fiscales.

En este contexto, se debe destacar la memoria al Congreso de 1847 del Ministtro de Hacienda Manuel del Río que cuestionó la Ley de 1828 que permitió enajenar las tierras de indígenas, porque al cambiar la propiedad en favor de las castas (esto es, de los demás peruanos) la recaudación tributaria disminuía, pues la contribución de castas y la predial en su caso no eran aplicables y, en todo caso, no existía la organización administrativa necesaria para cobrarlos, toda vez que la contribución de indigenas continuaba recolectándose a través de mecanismos de dominación regional subsistente en los primeros años de la República.

\subsection{Vigencia real de la comunidad}

La comunidad indígena nunca llegó a ser concebida como una organización social ni como unidad jurídica. Para el legislador civil sólo fue una forma colectiva de propiedad que debía ser abolida. No obstante, para el resto del derecho la comunidad indígena sí tuvo reconocimiento e identidad.

Desde la Colonia la comunidad indigena tenía todas las características de una unidad jurídica y participaba de todas las características que en la legislación moderna se requiere para identificar una persona jurídica. La contribución de indígenas, por ejemplo, no era el tributo personal sino un tributo común a la comunidad. Era la comunidad, el "sujeto pasivo" de la relación tributaria. Para este efecto, era irrelevante que la tasa tributaria asignada a la comunidad guardase relación con el número de comuneros (tributarios), ésta era sólo una forma de calcular la contribución. Esto es así, porque las tasas se determinaban después de cada censo, y las incorporaciones o exclusiones de comuneros en los períodos intermedios en nada debían afectar la tasa pre-establecida (véase Costa 1981, Pág. 14). 
Pero no sólo la comunidad de indígenas subsistió como unidad jurídica para efectos fiscales. La comunidad fue reconocida en el decreto de Castilla del 6 de agosto de 1846. Las resoluciones del 15 de enero y del 30 de abril de 1849 reconocieron el derecho de las comunidades campesinas sobre las tierras adquiridas a la Colonia, adquiridas mediante pago en dinero y acreditadas por posesión inmemorial. En igual sentido se pronuncia la resolución legislativa del 11 de octubre de 1893. Finalmente el Código de Aguas y la Ley de Caminos del 3 de noviembre de 1916 constituyen precedentes inmediatos del reconocimiento legal de la comunidad, hasta su consagración definitiva en la Constitución de 1920.

Para el analista civil no debe escapar cómo a pesar de existir la comunidad para otros efectos jurídicos no se le haya reconocido efectos sobre la posesión que ejercían sobre las tierras, a pesar de que el Código de 1852 reguló la posesión y la adquisición prescriptiva de dominio. En este caso, pesó más la idea liberal de abolir la comunidad. No obstante, a pesar del silencio del Código Civil y luego de casi un siglo de búsqueda pertinaz por abolir las comunidades, el Estado se vio en la necesidad de reconocer la existencia legal de la comunidad.

\subsection{El indio y la comunidad como sujetos políticos}

A pesar del mensaje liberal del Código Civil, éste no llegó a igualar a los indios en todos los derechos. Cuidó claramente de diferenciar los derechos civiles de los políticos. Así el Art. 32 establecería que "los derechos civiles son independientes de la calidad de ciudadano".

Es relevante destacar la discusión ideológica en torno a los derechos políticos del indio y la comunidad. El derecho de sufragio fue reconocido en la ley del 12 de octubre de 1847 que habilitaba en el ejercicio de la ciudadanía a los indígenas y mestizos mayores de 25 años o casados aun cuando no supieran leer y escribir. Al debatirse una reforma constitucional sobre el derecho de sufragio del indio en 1849, Bartolomé Herrera pronunció su doctrina. ". . . el derecho no tiene su origen en la voluntad humana sino en la naturaleza. No es un castigo a los indígenas y mestizos declarar que no pueden votar, porque se puede carecer de un derecho no sólo 
por delito sino también por incapacidad natural. La naturaleza humana en todos es la misma, pero cada ser humano se desenvuelve según sus facultades. El niño y la mujer ven restringidos sus derechos civiles, así también el analfabeto debe carecer de derechos políticos, aunque forme la mayoría de la población del país. . negar el sufragio a la mayoría de los indios no es degradarlo (al contrario) darles participación en la política es la verdadera obra maldita de degradación y de repugnante envilecimiento de esa raza infeliz ..." (Basadre 1939 Tomo III, Págs. 226-227). Si bien la posición de Bartolomé Herrera fue derrotada en el Congreso, no se debe olvidar que ejerció gran influencia desde la cátedra que ejercía en el Convictorio de San Carlos.

Posteriormente, en la discusión de la Constitución de 1920, las tendencias liberales aún seguían dando una batalla ideológica contra el reconocimiento de las comunidades. J.M. Rodríguez señalará que ". . . la nación no puede reconocer en su seno a una entidad distinta de las que constituyen la nacionalidad. . . cuando nosotros vamos a incrustar la idea de que la nación reconoce la existencia de las comunicades indigenas, yo creo que establecemos que la Nación está reconociendo en su propio seno una entidad heterogénea. . nosotros vamos a legislar por razón de la diferencia de personas cuando debiéramos hacerlo por la naturaleza de las cosas, como lo manda la Constitución .. .' (Costa 1981 Págs. 55-56).

En consecuencia, el mensaje liberal del Código Civil por abolir la situación del indio y su comunidad también tuvo correspondencia en elementos conservadores y tradicionales que, unieron al propósito liberal sus propios propósitos aristocráticos.

\subsection{Ideología, buena fe y resultado final}

En resumen, el Código Civil inspirado en los mismos principios los primeros decretos de la República sobre la tierra, reforzó y continuó la política de desvinculación y movilización de la propiedad agraria. Para ello, el Código confirmó tácitamente la abolición legal de las comunidades indígenas y de las vinculaciones de dominio; pero mantuvo la tradición de las "manos muertas", al regular las vinculaciones eclesiásticas. 
Para el legislador civil, el indio no tuvo la connotación ideológica que tuvo para los elementos conservadores y aristocráticos ni tampoco previó su rol en la economía. Por el contrario, optó por convertirlo en un pequeño propietario, sin considerar los elementos históricos ni la forma cómo el indio se articulaba con su comunidad y con su proceso productivo.

No es aventurado decir, que el indio fue más un tema de ideología nacional. En realidad, San Martín y Bolívar, Sánchez Carrión y Luna Pizarro y muchos otros próceres no fueron terratenientes, de modo tal que su vinculación con el indio no pasó por la lucha de intereses que el propio indio sufría con el latifundio. Desde la fundación de la República la idea del indio desapareció para ser confundido como un peruano más, así en 1821 San Martín mandó que a los indígenas se les diese el nombre de peruanos y declaró que estaban eximidos de los servicios que prestaban como mitas, pongos, encomiendas y yanaconas (Decretos del 27 y 28 de agosto de 1821, citados por Basadre en 1939 Tomo I, Pág. 223).

Es importante reconocer que para el legislador no estuvo ausente la idea de explotación en que vivía el indio. ". . vosotros indios... sois el primer objeto de nuestros cuidados. Nos acordamos de los que habeis padecido y trabajamos para hacerlos felices. Vais a ser nobles, instruídos, propietarios y representantes entre los hombres todo lo que es debido a vuestras virtudes..." es la idea común de los primeros constituyentes en 1822 , en una proclama transmitida en quechua.

Sin embargo, la situación del indio sufrió el espejismo de la importación de las disciplinas y tendencias jurídicas liberales prevalecientes. Al abstraer la condición del indio y formularla en una igualdad juridica abstracta sin los mecanismos de protección y promoción que requirían para superar la dominación del latifundio, el propósito declarado de los legisladores tuvo un resultado totalmente distinto. Fueron los legisladores tan inocentes frente al propósito de liberar al indio que mediante normas teóricas lograron contradecir su propósito y acentuar la dominación (véase Basadre 1939 - Tomo I Págs. 262-263). 


\section{El matrimonio: contrato o sacramento?}

El Código Civil estableció que "el matrimonio se celebra en la República con las formalidades establecidas por la Iglesia en el Concilio de Trento"' (art. 156).

Durante el proceso de formación del Código fue evidente el conflicto entre las tendencias liberales y conservadoras, En relación a la disposición sobre el matrimonio, Vidaurre propuso en su proyecto incluirlo como contrato. También debió aceptar lógicamente el divorcio, pero sólo aceptó incluirlo como separación perpetua sin ruptura de vínculo. Dirá que “. . a un pueblo soberano no se le dan leyes sobre sus votos públicos. El Perú no recibiría con placer el proyecto, si presumiese que se mezclaban en él, aunque remotamente, doctrinas que se tienen por antireligiosas. Trabajen aún los filósofos en propagar la luz. Tal vez antes que la noche me deje en una oscuridad eterna, presenciaré con satisfacción derogadas algunas leyes que voy a proponer..." (véase Basadre 1937 Págs. 327 a 338). El proyecto de Vidaurre no fue tomado en cuenta, no podía prosperar por su anticlericalismo que laicalizaba el matrimonio, omitía toda referencia sobre los sacerdotes y atacaba la herencia.

El primer anteproyecto de Código Civil presentado al Gobierno en 1847 también recogió la propuesta de Vidaurre de instituir al matrimonio como contrato, conforme la tendencia liberal prevaleciente. Es relevante que en el oficio de remisión del proyecto, la comisión considerara importante destacar este hecho. Así en el oficio que redactó Pérez de Tudela el 18 de julio de 1847 indicó que "... tres señores de los que componen la comisión de Códigos consideran al matrimonio separado del sacramento y dos como inseparable, según ha estado en el Perú desde la promulgación del evangelio y se observa en los países católicos en donde no hay diversidad de cultos y que la mayoría de los habitantes de la República no se hayan en estado de admitir novedades que turbarían las conciencias y la expondrían a grandes abusos en perjuicio de la Religión y el Estado ..." (Basadre 1937 - Págs. 349-350).

Como se conoce la propuesta mayoritaria no prosperó. E1 matrimonio y la familia fueron regulados por el Código Civil de 
una manera tradicional, renunciando al estado liberal a regular las instituciones conforme a las tendencias prevalecientes y sometiéndolas a las regulaciones y autoridad de la Iglesia Católica. Esta autoridad sólo se ve atenuada por la implementación de los registros del estado civil; pero esta reforma laica no se puso en vigencia hasta 1875 , y la Iglesia conservó su vigilancia sobre los tres actos más importantes de la vida humana: el nacimiento con la partidas parroquiales; el matrimonio con la subsistencia de la ceremonia religiosa refrendada por el acatamiento de la legislación civil y la muerte por extramaunción y el dominio religioso sobre los cementerios (Basadre 1937 Pág. 368).

También se filtró influencia alemana, a través de la ideología de Heinecio. Para Basadre esta influencia puede ser entendida en el hecho de que algunos elementos de la concepción del matrimonio como contrato están presentes cuando se concibe al matrimonio orgánica y socialmente, supuesto en el que sólo interesa los cónyuges y los hijos (véase Basadre 1937 Pág. 372).

La gran batalla sobre el matrimonio fue perdida por los liberales, en forma absoluta. Sin embargo, el doctor Oliveira señala en su memorándum sobre el matrimonio presentado a la Comisión Reformadora del Código Civil en 1923, que la tónica de la época hubiera permitido un derecho matrimonial que, sin herir las creencias religiosas, excitara la abjuración absoluta que el Código de 1852 hizo de los foros civiles, y que permitiese el matrimonio de los no católicos. Cita el Dr. Oliveira el proyecto de Código Civil Español de 1851 que entregaba las causas del divorcio a los tribunales civiles (Basadre 1937 - Pág. 355). El matrimonio civil para no católicos fue regulado finalmente por la ley del 23 de diciembre de 1897.

Este es otro elemento en el que el legislador civil deja de lado las tendencias liberal y moderna prevalecientes y opta conscientemente por mantener elementos conservadores y tradicionales en la regulación de instituciones civiles.

\section{Los esclavos}

San Martín en 1821 y las Constituciones de 1828 y 1834 habían establecido que "nadie nacía esclavo en la República y que 
no entraba al Perú ninguno que no quedara libre". Salaverry por Decreto del 10 de marzo de 1835 estableció la legalidad del comercio e importación de esclavos de otros países americanos, atendiendo las presiones de los hacendados de la costa, en clara contradicción con las Constituciones de 1828 y 1834.

La Constitución de 1839 suprimió la segunda parte de las normas constitucionales de 1828 y 1834, aquella que establecía ". . . que no entraba al Perú ninguno que no quedara libre. ..", autorizando así tácitamente el tráfico de esclavos y confirmando las disposiciones de Salaverry.

Previamente, la ley del 24 de diciembre de 1829 habia dispuesto que los libertos (hijos de esclavos declarados libres) quedaban bajo el patronazgo de los amos de sus padres hasta la edad de 50 años. Al permitir la cesión del patronazgo, la ley permitió una forma velada de comercio, confundiendo la situación de los libertos para asimilarlos a la esclavitud. La norma tuvo otras consecuencias, al liberar a los amos de la obligación de mantener a los libertos cumplidos los 50 años, esto es, cuando perdiesen importancia económica.

El Código Civil reconoció expresamente la situación de los esclavos y los libertos, aunque sin modificar sustancialmente la situación precedente. La esclavitud fue finalmente abolida dos años después de la vigencia del Código, mediante decreto del 3 de diciembre de 1854. En rigor, esta segunda emancipación de la esclavitud sólo fue posible mediante la indemnización de trescientos pesos por esclavo, facilitada por los ingresos fiscales provenientes de la explotación del guano.

Más allá de la sobrevivencia del régimen de la esclavitud, lo importante es precisar que el codificador no aceptó incorporar elementos modernos en el tratamiento, aun cuando normas constitucionales y los mismos principios liberales sustentaban una opción abolicionista. El análisis de este aspecto revela una vez más las contradicciones $\mathrm{y}$ tensiones entre las opciones tradicionales $\mathrm{y}$ modernas. El codificador mantendrá lo tradicional cuando los intereses en juego se lo exijan. Después de la abolición de la esclavitud, formas más sutiles de servidumbre contractual fueron im- 
puestas para permitir mano de obra gratuita en la explotación del guano y la producción de las haciendas costeñas.

\section{Reflexión final : lo nacional y lo importado}

¿Por qué el Código Civil no recogió congruentemente los dispositivos liberales prevalecientes y por qué, en todo caso, los que recogió no lograron los objetivos perseguidos? Creo que la respuesta se encuentra en el proceso de formación del Código. Cuando un legislador importa un Código o una ley lo hace justamente porque asume su significación cultural e ideológica. Al recepcionar la ley foránea busca, precisamente, poner en vigencia en su medio social la concepción o el pensamiento jurídico de quien lo inspira (véase Hurtado 1979 Págs. 20 y siguientes).

El pensamiento y la ideología liberal se recogieron del Código Francés. Para la Francia del Siglo XIX, el Código confirmó la desaparición de la aristocracia feudal y adoptó los principios sociales de la Revolución Francesa: la libertad personal y la igualdad ante la ley, dinamizó los contratos y reguló los patrimonios. Como toda la reforma de la burguesía liberal, a los que nada tenían no tuvo nada que darles y al proclamar el trabajo libre y a los ciudadanos iguales ante el derecho, abandonó a los comunes (los asalariados) a todos los azahares de la concurrencia económica, como si sus brazos fuesen una mercancía cualquiera (véase Basadre 1954, Págs. 364-365). En suma, la modernización liberal en Francia pretendió liberar fuerzas productivas ahogadas por el peso de la tradición y por los mecanismos de control social de la aristocracia.

Situación distinta fue la del Perú del siglo XIX. Los elementos liberales no fueron incorporados para modificar la sociedad tradicional ni para transformarla. El resultado fue que los elementos tradicionales absorbieron la dosis de modernización liberal y la hicieron compatible con su denominación aristocrática. Es cierto que con la fundación de la República la aristocracia española desapareció pero sólo para ser sustituida por una nueva aristocracia criolla (la oligarquia terrateniente), no hubo una nueva clase que asumiera un rol distinto en la sociedad.

El derecho dentro de este contexto ideológico, sólo fue un medio para organizar políticamente la sociedad. El derecho y, en 
nuestro caso el Código Civil, no fueron utilizados sino para diseñar un Estado antes que un mercado. De ahí que la mayor preocupación durante la primera mitad del siglo XIX haya sido la redacción de Constituciones en lugar de la redacción de los Códigos básicos. Entre los elementos tradicionales y modernos hubo un eclecticismo superficial en que ambos elementos aparecen precariamente combinados y no son precisamente un modelo de coherencia y de rigor. La prosopopeya verbal cubrió en el debate las deficiencias de razonamiento.

Esta misma fragilidad en la importación y recepción del pensamiento liberal explica las violaciones frecuentes de los principios y que tales violaciones sean procesadas y asimiladas sin repercusiones sociales catastróficas. La libertad y la igualdad para gran parte de los peruanos fue ilusoria. Es probable que el liberalismo sólo haya sido importado como un soporte para defender la independencia política porque el criollo del siglo XIX vivía la dominación española como una ofensa, pero fue incapaz de adecuar el pensamiento liberal para dinamizar una nueva forma de producción y articulación social (véase 'Trazegnies 1980).

¿Tuvo el codificador de 1852 alguna otra alternativa desde la dogmática jurídica? Estimo que sí. Frente a la influencia del Código Francés, se desarrollaba en Alemania la escuela histórica y la influencia de Savigny. Para esta escuela el derecho es un producto espontáneo del pueblo, reivindicando la costumbre jurídica nacional contra la ley escrita que podía imponer la importación de un derecho extranjero o exótico.

Lamentablemente la escuela histórica no impidió la codificación prevaleciente del siglo XIX y en el Perú no se recibió la influencia de Savigny, a pesar de que Vidaurre lo cita en su proyecto de Código Civil de 1834. El desapego del Código Civil de 1852 a la costumbre repercutió contra el derecho indígena, pero no tuvo reparos en aceptar los elementos tradicionales al regular el matrimonio y los esclavos. En este aspecto, el codificador renunció también a una sana técnica legislativa de la Colonia que mantuvo elementos de regulación jurídica prehispánicos. Así, la cédula de Valladolid del 6 de agosto de 1555 incluía la norma que estableció lo siguiente: “... Ordenamos y mandamos que las leyes y 
buenas costumbres que tenían los indios para su buen gobierno y policía y usos y costumbres derivadas y guardadas después que son cristianos y que no encuentran con nuestra sagrada religión, ni con las leyes de este libro y las que han hecho y ordenado de nuevo, se guarden y ejecuten y siendo necesario por la parte las aprobamos y confirmamos..." (véase Basadre 1937 Págs. 377-378).

Como nota final se debe precisar que los elementos aristocratizantes sobrevivieron incluso en la relación jurídica de los propios criollos a pesar del pensamiento liberal. Por ejemplo, los Estatutos del Colegio de Abogados de Lima de 1804 establecieron que para ser miembro del Colegio el postulante debía acreditar “. . . ser español, hijo legítimo o natural, descendiente de cristianos viejos, libre de toda mala raza de moros, judíos, penitenciados o comprendidos en nota de infamia, con expresión de la limpieza de sus padres y abuelos. . . quedando absolutamente excluídos de la matrícula los bastardos, espurios y adulterinos". Para Trazegnies, era muy probable que hacia 1870 en que se reformó el Estatuto, las regulaciones aristocráticas $\mathrm{y}$ discriminatorias no tuvieran mayor vigencia real. Pero destaca que lo importante fue que hasta esa fecha no habian sentido la necesidad de modificarlo. De este Colegio eran integrantes los legisladores y codificadores (véase Trazegnies 1980-B Págs. 164-165).

Las opciones del Código Civil de 1852 tratadas en este trabajo no lograrían sobrevivir. La Constitución de 1920 reconoció finalmente la existencia jurídica de la comunidad, el matrimonio fue finalmente tratado como contrato y como sociedad en el Código Civil de 1936 y la esclavitud fue formalmente abolida en 1854. 
BIBLIOGRAFIA

(1) BASADRE, JORGE. 1937. Historia del Derecho Peruano, 2da. Edición, Ediciones Gráficas S.A. 1986.

(2) BASADRE, JORGE. 1939. Historia de la República del Perú. 6ta. Edición, Editorial Universitaria.

(3) BASADRE, JORGE. 1954, Los Fundamentos de la Historia del Derecho. 2da. Ediciōn, Ediciones Gráficas S.A.

(4) BONILLA, HERACLIO 1972. La Independencia en el Perú. Perú Problema, IEP, Lima.

(5) BONILLA, HERACLIO. 1974. Guano y Burguesía en el Perú. IEP Lima.

(6) COSTA, GINO. 1981, La función legislativa del Estado frente a la Comunidad Campesina entre 1920 y 1980. Tesis Bachiller en Derecho, PUC, Lima.

(7) DE LA GRASSERIE. ? Código Civil 1852. Juicio del Código.

(8) HALPERIN, JULIO. ? Historia Contemporánea de América Latina. Alianza Editorial, Madrid.

(9) HURTADO, JOSE. 1979. La Ley Importada. CEDYS, Industrial Gráfica.

(10) MANRIQUE, NELSON. 1987. Mercado Interno y Región: La Sierra Central 1820-1930. DESCO, 1987.

(11) MARIATEGLI, JOSE C. 1928. 7 Ensayos de Interpretación de la Realidad Peruana. 48 Edición, Empresa Editora Amauta 1986.

(12) PASSARA, LUIS. 1970. El Rol del Derecho en la Epoca del Guano. Revista DERECHO - PUC, Lima 1970.

(13) PASSARA, LUIS. 1967. La Comunidad Indígena como Persona Jurídica. Tesis Bachiller en Derecho, PUC - Lima.

(14) REMY, MARIA ISABEL. 1986. Tierra y Poder: La dinámica del Cuzco en el Perú Republicano 1824-1880. Tesis Escuela de Altos Estudios en Ciencias Sociales - París.

(15) SANCHEZ, NICOLAS. 1978. Indios y Tributos en el Alto Perú. Historia Andina, IEP, Lima. 
(16) TRAZEGNIES, FERNANDO DE. 1980. La Transferencia de Filosofías Jurídicas. Revista DERECHO - PUC Lima 1980.

(17) TRAZEGNIES, FERNANDO DE. 1980-B. La Idea del Derecho en el Perú Republicano del Siglo XIX. Fondo Editorial PUC, Lima. 